\title{
Survey on Green Computing: Vision and Challenges
}

\author{
Ibtehaj AIMusbahi \\ Department of Electrical and \\ Computer Engineering, FOE, \\ King Abdulaziz University, \\ Jeddah, KSA
}

Ola Anderkairi

Department of Electrical and Computer Engineering, FOE, King Abdulaziz University, Jeddah, KSA

\author{
Reem H. Nahhas \\ Department of Electrical and \\ Computer Engineering, FOE, \\ King Abdulaziz University, \\ Jeddah, KSA
}

\author{
Bashair AlMuhammadi \\ Department of Electrical and \\ Computer Engineering, FOE, \\ King Abdulaziz University, \\ Jeddah, KSA \\ Hemalatha M. \\ Department of Electrical and \\ Computer Engineering, FOE, \\ King Abdulaziz University, \\ Jeddah, KSA
}

\begin{abstract}
Nowadays, the usage of computers is considered a daily necessity. The extravagant practice involving computer technology demands certain degrees of responsibility on the part of users to avoid or minimize harmful impacts associated with negative affecting the environment. The use of computers, their accessories and resources is the environmentally responsible. Green computing is emerging as a prompting solution to this crisis. Green technology is becoming more desired for the public through the work of governments and environmental organizations, and has been growing recently. Previously, the only focus was on IT equipment power processing while the energy's infrastructure, cooling and data center space is always considered available, certain, and their cost is reasonable. Nowadays, the infrastructure of any data center is the factor that an organization focuses on because it is considered one of the main factors that determine the amount of power consumption in any data center. Behind this change, there are other factors causing the increasing interest of the green computing issue such as fast growing loads of energy cost, growing realization of global warming problems, and increasing the interest of national energy security. This article presents the current and future trends and the challenges that face the researcher in a field of Green Computing to minimize and reduce associated harmful impacts on the environment.
\end{abstract}

\section{Keywords}

Green Computing - Green Cloud Computing - Environmental Protection Agency (EPA) - IT.

\section{INTRODUCTION}

The effective and efficient use of computers and related technology by humans in an ecofriendly manner is known as Green Computing. Green Computing aims to minimize the impact of carbon emissions on the environment. It is also "the study and practice of designing, manufacturing, using, and disposing of computers, servers, and associated subsystem efficiently and effectively with slight or no impact on the environment" [1]. Reducing the hardware needs of power and cooling systems are the goals that enhanced research and development of green computing trying to achieve. Nowadays, not only the companies have an increased awareness of green technologies, but consumers have also gained more awareness in the last decade. Therefore, this has increased demand for environmentally friendly products in their homes and workplaces. In order to protect the human health, environment and save energy, green computing studies have become the utmost requirement [2]. In addition to that, low operational expenses in today's competitive world is an advantage [3].

The Green Computing started in 1991 when the Environmental Protection Agency (EPA) introduced the "Green Light" program. Then in 1992, the "Energy Star" program followed the same concept. These programs were based on energy efficiency specifications. Although the concept of green computing has been there for a long time, it is only in the last decade that the world has witnessed the fast growth of this concept. The main key drivers for the research to develop this concept are the growth of cloud computing and the amount of energy consumption that led to the increase of the carbon footprint on the environment [4].

Green Computing is important in IT systems although it presents problems to system designers. Therefore, the designers need to find solutions to reduce the energy consumption during the system design. Designing cheap and low-power-consumption systems are important challenges to designers because green computing involves all aspects of IT systems.

This survey discusses the current trends in the field, explores the challenges of Green Computing and discusses the future trends towards Green Computing. Finally, this survey will be concluded.

\section{CURRENT TRENDS IN GREEN COMPUTING}

As green computing trends aim to utilize resources efficiently, there are several fundamental steps that researchers have taken into consideration. Increasing the performance of computing while reducing the energy utilization and the carbon emission, one of the main threats on the environment, is the optimum goal. To do that, several approaches have been taken by the organization including:

\subsection{Power management techniques}

In order to reduce greenhouse gas emissions produced by the organizations, energy consumption should be reduced. To do that, the organizations have started to adopt several techniques beginning with using devices that are more energy efficient. According to the Environmental Protection Agency "around $30 \%$ to $40 \%$ of personal computers are kept 'ON' after office 
hours and during the weekend and even around $90 \%$ of those computers are idle" [1]. To save power, the computers that are not in use should activate the hibernate mode which can save up to $96 \%$ power consumption. Another mode could be used which is the "stand-by" mode which can save up to $80 \%$ energy consumption. The organizations have also start to use handheld devices rather than PC's because desktops computers consume $80 \%$ more power than handheld devices [3].

Another technique is energy efficient coding which means reducing the software usage of the hardware. More efficient algorithm will lead to reduce the number of resources needed to complete a certain computing function. By combining these two techniques, energy savings will be greater [3].

\subsection{Virtualization}

The major trend in green computing nowadays is Virtualization. Virtualization of computer resources is the process of running multiple computer systems on one set of physical hardware. In order to extend the work of old datacenters, the organizations now do not need a new set of hardware to do new tasks. They just need the virtualization method to run several operating systems simultaneously on one host computer. The advantages of this method are that the organization can support new applications by maintaining the same amount of hardware, total space, and cooling consumption [1] [3] [4].

\subsection{Improved repair, re-use, recycling and disposal}

Based on the Gartner estimations "over 133,000 PCs are discarded by U.S. homes and businesses every day and less than 10 percent of all electronics are currently recycled" [1]. The harmful toxic gases from the e-waste affecting the environment should be eliminated. The recycling trend in green computing tends to keep computing equipment materials like lead and mercury out of landfills and reusing old computer parts to repair or upgrade other computer systems will save energy, reducing the generation of E-waste affecting the environment [1] [3] [5].

\subsection{Data center consolidation and optimization}

With the data center being considered as the main source of power consumption in any organization, serious attention should be paid to it. Starting with infrastructure equipment of the data center such as the power supplier, storage devices network and cooling equipment. To reduce energy consumption of the data center, several steps should be taken by the organizations. The first one is the selection of the right and efficient equipment to be used in the information systems. The second step is take consideration of the current and future requirement of the data center in the initial stage of designing the cooling system. Thirdly, while designing the electrical system of the data center, a consideration of future loads should be taken into account [1].

\subsection{IT product and eco-labeling}

An additional trend toward green computing is the "eco-label" which has been supported by several organizations around the world. These eco-labels are given by organizations to IT products based on several factors aiming to save the environment. The factors include the ability of recycling the system, noise energy consumption etc. [1].

\section{GREEN COMPUTING CHALLENGES}

Today, computers consume a great portion of the world's available energy. Moreover, computing needs to growing faster, therefore this extravagant practice of using computing technology is considered as the major challenge faced in the field. For that, green computing should focus on reducing the IT infrastructure and equipment associated costs as natural resources are being consumed greatly. While the focus was concentrated on the services of infrastructure and computing efficiency. This shift considers a super challenge for the Information technology (IT) industry. Also, the researchers in the green computing were determined some of the challenges that Green Computing is facing today which are as following [6] [7]:

- Return of Investment: one of the difficult things that faces green computing is convincing companies and their stakeholders to invest in environmentally friendly computing. A setback is that they want to see an immediate impact but it takes substantial amount of time for the investment to show real benefits and changes.

- Disposal of Electronic Wastes: the biggest dilemma is electronic wastes and trying to change materials that are used in manufacturing of computers and chips which is hazardous and hard to dispose compared to more eco-friendly materials.

- Power Consuming: Leaderships in the field are trying to find a generation of IC chips that have high efficiency and give higher performances without consuming too much power but this is not a simple process, it takes a huge effort, amount of a lot of time, and needs high levels of skilled engineers to reach and achieve this goal.

- Increase in energy requirements: some people need or prefer to use high processors to achieve their tasks. However, these requirements need a great amount of power with the green computers with the same specifications considered extremely expensive such as the Apple's power range of computers including their iMacs that are incredibly green [6].

\section{FUTURE TRENDS IN GREEN COMPUTING}

Green Computing has begun to be propagated in the past few years, and has become increasingly important as the impact of greenhouse gas production has on climate change and global warming has been realized. Besides the ecological issues, the economic needs are also a problem because both electrical requirements of IT and energy costs are a continuously growing trend. The future plans towards green IT should include efficient services and possible options to get energy saving because green computing in the future is going to be based on efficiency, rather than reduction in consumption. Although current research on green computing has handled some issues, there are other issues requiring further investigation [3] [6] [7]. Green Cloud Computing is one of the motions towards green technology. The cloud computing initiative provides data and services to users worldwide. The efficient performance of the cloud computing data center has measured using different factors identified by researchers. So, usage of cloud computing has been found a friendly solution to overcome environmental issues [8] [9] [10]. 


\section{CONCLUSION}

The green computing movement has witnessed an increase in the last decade. The organizations and researchers have put in a lot of effort to achieve eco-friendly technologies. Power management techniques, virtualization, improved repair, reuse, recycling and disposal, data center consolidation and optimization, and IT product and eco-labeling are the approaches that have been taken so far by the organizations towards green computing. Despite the challenges that are facing the researchers in the field of green computing, the computing industry witnessed an improvement in energy efficiency.

\section{REFERENCES}

[1] T. R. Soomro, "Green Computing: From Current to Future Trends," International Journal of Social, Behavioral, Educational, Economic, Business and Industrial Engineering, 2012.

[2] P. V. a. J. T. Hemalatha M., "Scheduling BTS Power Levels for Green Mobile Computing," Journal of Green Engineering, 2015.Froehlich, B. and Plate, J. 2000. The cubic mouse: a new device for three-dimensional input. In Proceedings of the SIGCHI Conference on Human Factors in Computing Systems

[3] S. Singh, "Green Computing Strategies \& Challenges," IEEE, 2015.
[4] R. R. Harmon, "Sustainable IT Services: Assessing the Impact of Green Computing Practices," 2009.

[5] S. Dutta, "Green Computing: A Green Approach towards IT," IEEE, 2016.

[6] P. Rani, "CHALlENGES TO THE SUSTAINABLE GREEN COMPUTING," International Journal Of Advance Research In Science And Engineering , 2013.

[7] D. Wang, "Meeting Green Computing Challenges," International Symposium on High Density packaging and Microsystem Integration,, 2007.

[8] M. Z. Qilin Li, "The Survey and Future Evolution of Green Computing," IEEE/ACM International Conference on Green Computing and Communications, China, 2011.

[9] D. U. L. Prof. Riyaz A. Sheikh, "Green ComputingEmbrace a Secure Future," International Journal of Computer Applications, Nagpur, 2010.

[10] M. C. Prof.Sanjeev Thakur, "Towards Green Cloud Computing : Impact of Carbon Footprint On Environment," IEEE, 2016.

[11] D. P. R. S. Rubyga. G1, "A Survey Of Computing Strategies For Green Cloud," IEEE, 2016.

[12] A. C. T. S. S.Gavaskar, "Mobile Apps For Green Cloud Computing Performance Measure," IEEE, 2016. 